\title{
POLÍTICA E LITERATURA NOS CADERNOS DO CÁRCERE: NOTÍCIAS DE UMA PESQUISA
}

\section{Daniela Mussi ${ }^{1}$}

Resumo: O presente texto busca apresentar a primeira parte da pesquisa de dissertação "Política e Literatura nos Cadernos do Cárcere". Esta parte consiste na apresentação de uma síntese da pesquisa teórica sobre os antecedentes e desenvolvimento do conceito fundamental para Gramsci, o conceito de hegemonia. A importância desse conceito, já destacada no projeto de mestrado, para a compreensão do vínculo fundamental entre a questão literária, cultural e política, fez necessária uma investigação teórica e histórica preliminar dos sentidos e fontes possíveis para hegemonia antecedentes ao seu desenvolvimento pelo marxista sardo e que constituíram um ambiente para tal. A partir disso, apresentamos um estudo do conceito nos Cadernos do Cárcere, fundamental para, posteriormente, traçar as conexões possíveis entre política e literatura através da hegemonia.

Palavras-chave: Antonio Gramsci; política; literatura; hegemonia; Cadernos do Cárcere.

Resumen: En este trabajo se presenta la primera parte de la tesis de investigación de maestria "Política y Literatura en los Cuadernos de la Cárcel". Esta parte presento una síntesis de la investigación teórica sobre los antecedentes y desarrollar del concepto central en Gramsci, el concepto de hegemonía. La importancia de este concepto, tal como se destaca en el Proyecto de investigación, para entender el vínculo fundamental entre la cuestión de las obras literarias, culturales y políticas, hizo necesaria una investigación histórica y teórica preliminar de los sentidos y las posibles fuentes del concepto de hegemonía antecedentes a su desarrollo por el sardo marxista y que constituye un ambiente propicio para ello. De esto, se presenta un estudio del concepto en los Cuadernos de la Cárcel, esencial para localizar posteriormente las posibles conexiones entre la política y la literatura a través de la hegemonía.

Palabras-clave: Antonio Gramsci, política, literatura, hegemonia, Cuadernos de La Cárcel

Abstract: This paper presents a synthesis of theoretical research on the antecedents and develops of Gramsci's central concept, the concept of hegemony. The importance of this concept to understand the critical link between literary, cultural and political questions, made necessary a preliminary historical and theoretical investigation of the senses and possible sources for hegemony background to its development by the Sardinian Marxist. From this, we present a study of this concept in the Prison Notebooks, essential to trace the possible connections between politics and literature through hegemony.

Keywords: Antonio Gramsci: politics, literature, hegemony, the Prison Notebooks

${ }^{1}$ Mestranda em Ciência Política na Universidade Estadual de Campinas. danixhm@yahoo.com.br 


\title{
CONSIDERAÇÕES PRELIMINARES
}

A idéia da pesquisa "Política e Literatura nos Cadernos do Cárcere" surgiu no segundo semestre de 2008, com um trabalho final escrito para o curso eletivo sobre o pensamento de Antonio Gramsci, ministrado pelo Prof. Alvaro Bianchi para estudantes de Ciências Sociais na Universidade Estadual de Campinas. O curso enfatizava a complexidade da investigação sobre os Cadernos, a necessidade de pesquisar os diversos "tempos" de um pensamento, cristalizados nas páginas de Gramsci prisioneiro do fascismo (cf. BIANCHI, 2008; cf. BARATTA, 2004). O marxista sardo, afinal de contas, nunca publicara seus cadernos, muito menos compartilhara a difusão de suas reflexões carcerárias na cultura italiana, iniciada mais de dez anos após sua morte em 1937.

O desafio de compreensão de uma obra que não traz senão frágeis indicações de seu começo, meio e fim, composta por muitos fragmentos de texto - notas, parágrafos - era reforçado pelo próprio Gramsci, ao indicar “questões de método”2:

\begin{abstract}
Se se quer estudar uma concepção de mundo que nunca foi exposta sistematicamente por seu fundador (e cuja coerência essencial se deve buscar não em cada escrito particular ou série de escritos, mas em todo o desenvolvimento do variado trabalho intelectual em que os elementos da concepção estão implícitos), é preciso fazer preliminarmente um trabalho filológico minucioso e conduzido com escrúpulos máximos de exatidão, de honestidade científica, de lealdade intelectual, de ausência de qualquer preconceito e apriorismo ou posição preconcebida (Q.16, §2, p. 1840-1841).3
\end{abstract}

Dito isso, cabe assinalar que a crítica da literatura e das artes em geral especialmente do teatro - não são temas “carcerários”, mas intimamente conectados com a experiência intelectual e político-militante de Gramsci. Essa constatação, embora não invalide o estudo da literatura com base nos escritos dos Cadernos, impõe uma tensão à investigação e a necessidade permanente de tradução das questões literárias para o contexto político italiano e Europeu, pensado por Gramsci antes mesmo de ser preso.

\footnotetext{
2 Antes mesmo da prisão, é possível observar uma atitude rigorosa de Gramsci na pesquisa do desenvolvimento intelectual, das idéias adquiriam estabilidade e eram permanentes nos pensadores com quem dialogava e polemizava. Seus artigos jornalísticos, por exemplo, recheados por figuras satíricas e metáforas - recurso muito usado para ampliar o alcance da compreensão dos temas políticos, econômicos e culturais discutidos - não eram, por isso, superficiais ou despreocupados em apresentar os pontos altos de uma concepção adversária. Gramsci estava preocupado em contribuir para a construção de uma concepção de mundo nova, e era inspirado por experiências políticas férteis para tal, como a Revolução russa e os soviets e os anos de ocupações de fábrica e criação de conselhos de fábrica em Turim.

3 As passagens dos Cadernos do Cárcere estão citadas de acordo com a paginação da edição crítica organizada por Valentino Gerratana (1975). A citação é apresentada da seguinte forma: Q. (número do Caderno), § (número do parágrafo), p. (número da página).
} 
Uma forma de alcançar o elo entre os Cadernos e a intensa atividade do marxista sardo antes de ser preso é articular permanentemente o estudo das passagens da obra com a reflexão contida nas cartas trocadas no período em que Gramsci escrevia na prisão. Em especial, cabe mencionar as cartas que eram trocadas com Tania Schucht, cunhada de Gramsci. Por vezes assumidas como "obra literária" - depois de sua publicação, as Cartas do Cárcere chegaram a ser premiadas na Itália como obra de enorme valor literário -, para a pesquisa passou a ser importante considerá-las como uma ferramenta de articulação dos diversos "tempos" do pensamento de Gramsci.

As cartas ajudaram, por exemplo, a desfazer a idéia simplista sobre o pensamento de Gramsci como o de um "sociólogo da cultura", pura e simplesmente. Pretende-se mostrar aqui que os planos de pesquisa no cárcere, anunciados por Gramsci nas cartas, fizeram com que o estudo da literatura passasse a exigir a compreensão da formulação dos conceitos políticos, especialmente o conceito de Estado. As intenções de pesquisa contidas nas cartas tornaram-se compreensível, ainda, o fato de Gramsci ter começado sua reflexão no Caderno 21 (Literatura popular), com um parágrafo intitulado "Conexão de Problemas". Aqui, o marxista afirmou que é preciso dar tratamento crítico e desapaixonado a todo um conjunto de problemas que "obcecam os intelectuais": unidade da língua, relação arte e vida, questão do romance e do romance popular, questão de uma reforma intelectual e moral, questão da "popularidade" do Risorgimento, etc. (cf. Q.21, §1,).

O tratamento desse conjunto de problemas, afirmava, poderia fornecer pistas para reconstrução das características fundamentais da vida cultural italiana e das exigências que eram por elas indicadas e propostas para solução. A literatura e as questões lingüísticas possuíam, portanto, um lugar no pensamento gramsciano na construção de uma pesquisa sobre "história da cultura" italiana. A pesquisa não teria caráter "sociológico", mas daria lugar a uma série de ensaios, procurando a forma literária mais adequada para a exposição. Gramsci pensava na construção de um "olhar monográfico" sobre os temas da história da italiana, articulado ao desenvolvimento de alguns conceitos (cf. Q.21, §1). 


\section{“CONEXÃO DE PROBLEMAS"4}

Em uma carta enviada do cárcere à cunhada Tania Schucht, de 17 de novembro de 1930, Gramsci apresentou a ideia de concentrar sua pesquisa em três ou quatro temas principais, entre eles o da "função cosmopolita dos intelectuais italianos até o setecentos", tema este vinculado à questão da língua italiana e sua relação com a organização da cultura italiana (LC, p.364). Interessava a Gramsci compreender, entre outros, o processo histórico no qual a língua falada pelo povo se separara da língua culta, aspecto característico da história dos intelectuais italianos. Nas primeiras frases do Caderno 21, escrito mais de quatro anos depois, em fevereiro de 1934, a tônica estava mantida: "são fenômenos (como o da dificuldade de unificação da língua) que precisam ser coordenados e subordinados para entender a questão da unidade cultural. É preciso evitar um tratamento abstrato e intelectualista da questão, sem perspectiva histórica exata e, portanto, sem que se formule uma solução político-social concreta e coerente” (Q.21, §1, p. 2107).

Para o marxista sardo, a questão literária estava vinculada ao problema "do equilíbrio de forças", mas não era até então estudada seriamente deste ponto de vista pelos intelectuais. Estes temiam que um estudo mais rigoroso dos fenômenos na cultura italiana "levassem a perigos para a vida nacional unitária da Itália" (Q.21, §1, p.2108). Mas o que isso quer dizer? Como o estudo "desapaixonado" da questão literária italiana poderia representar algum perigo à vida nacional?

Anos antes de compor o Caderno 21, em 3 de agosto de 1931, em outra carta a Tania, Gramsci afirmou que seu interesse em fixar pontos de reflexão como o da literatura partia da vontade de aprofundar o conceito de Estado e compreender o desenvolvimento histórico do povo italiano (LC, p.459-46o). A conexão entre o estudo da língua e literatura e a teorização dos conceitos políticos era uma chave imprescindível para conduzir com rigor uma pesquisa sobre a "vida nacional unitária" da península, e por isso Gramsci procuraria em outra nação o representante do vínculo entre literatura e Estado. Essa nação era a francesa.

Vinculada "às necessidades de um grande público", a questão literária estava conectada intimamente ao surgimento de uma hegemonia nova, moderna, como ponto de partida mais adequado para compreender as dimensões do problema da relação

\footnotetext{
4 "Conexão de Problemas" foi o título dado por Gramsci ao primeiro parágrafo do Caderno 21, "Literatura popular”. Nesse primeiro parágrafo, o marxista sardo apresentou uma série de questões pertinentes ao debate italiano sobre a questão literária, e busca conectá-los ao estudo da história da cultura italiana, do Renascimento até a formação do Estado nacional italiano no século XIX. O objetivo central aqui era o de estabelecer os nexos de investigação inevitáveis entre a literatura e a formação dos grupos intelectuais na península, para destacar seu caráter tradicionalmente cosmopolita, isto é, afastado das massas. Como veremos, Gramsci opôs a esse cosmopolitismo italiano o caráter nacional-popular da literatura francesa, "nascida" em 1789 (cf. Q.21, §1).
} 
entre política e literatura (ANGLANI, 1999, p. 12). Esse ponto de partida se estabelecia na reconstrução das condições determinantes e vicissitudes do momento em que uma nova organização do mundo se impôs como necessidade para as nações da Europa, e das consequências disso para o desenvolvimento das atividades de organização da vida moderna.

Num parágrafo intitulado "Literatura popular. Itália e França", Gramsci afirmava que até $1900^{5}$, a vida literária italiana, como tendência democrática enquanto pretendesse um contato com as massas populares - "é simplesmente reflexo francês da onda democrática francesa, que teve origem em 1789” (Q.21, §37, p. 1694). A artificialidade da vida literária italiana se devia ao fato de não existir na península uma "premissa histórica”, tal como na França. Essa "premissa" era justamente a formação do Estado nacional, que fundira a vida política francesa à vida das massas, e assim orientara o surgimento de uma literatura com vistas a amalgamar essas ao Estado. É importante destacar que o "provincianismo" literário italiano se manteve, para Gramsci, apesar do movimento de unificação do século XIX, o Risorgimento. A Itália possuía uma "vida nacional unitária”, mas não alcançara o patamar de Estado nacionalpopular, e matinha um "nexo" de coordenação e submissão com a França.

Cabe ressaltar também que a relação entre a política e a literatura não era considerada de maneira mecânica pelo marxista sardo, e sua compreensão nascia da articulação orgânica entre a atividade literária e o mundo histórico-cultural, critério que Gramsci considerava fundamental para que pudesse se aproximar "concretamente da realidade” moderna (Q.4, §49, p.476). É o que poderia ser chamado por "realismo gramsciano", em tensão com a tradição literária italiana, historicamente submissa ao Sacro Império romano e ao papado.

O desenvolvimento do conceito de uma hegemonia moderna - ou um novo equilíbrio de forças - se conectou ao estudo da questão literária na medida em que Gramsci estabelecia como centro da investigação sobre a vida literária italiana moderna a atitude popular frente às artes em geral, e em especial na literatura e no teatro. A experiência estética no capitalismo passara a ser um movimento de aspiração coletiva exercido pelos indivíduos “à 'bela' e interessante aventura, em oposição à 'feia' e revoltante que se dava em condições impostas por outros, não escolhidas” (Q.21, §13, p.2133).

Assim, como na questão da língua, existia em Gramsci o esforço em questionar o fenômeno no qual a literatura artística se separara da popular e cedia espaço a modalidades "degradadas, mas sentidas", de literatura, tal como o folhetim, o romance

\footnotetext{
5 A partir de 1900, a formação da "corrente idealista", representada por Giovanni Gentille e Benedetto
} Croce, impôs uma reflexão de tipo diferente em relação a atividade literária italiana (Q.21, §37, 1693). 
policial, o romance de aventura, etc., a "literatura dos humildes" (Q.21, §4, p.2113). De maneira geral, esse fenômeno era consequência de uma atitude de tipo "tradicional", "paternalista" e "divina" dos intelectuais frente às classes populares, resultado de um processo de afastamento radical que projetava a ilusão de indiscutível superioridade dos intelectuais em relação ao povo, e também entre filosofia superior em relação ao senso comum (Q.21, §3, p.2112). Esse fenômeno não era exclusivo da sociedade italiana, que era, aliás, um forte mercado para a "literatura dos humildes" francesa ao longo do século XIX. A diferença, salientava Gramsci, era justamente essa posição: os literatos italianos não eram sequer capazes de construir uma literatura "capitalista", "moderna”, e por isso se tornaram importadores da cultura nacional-popular francesa.

Com essa "conexão de problemas", Gramsci promovia uma abertura teórica e orgânica das dimensões cultural, política e histórica e das disciplinas científicas modernas, o que permitia abordar a questão literária não exclusivamente a partir de sua beleza estética, mas também, e principalmente, levando em conta a necessidade de determinado conteúdo intelectual e moral como expressão mais ou menos elaborada e completa das aspirações políticas e sociais profundas de um determinado público em certa fase de seu desenvolvimento histórico (Q.21, §4, p.2113).

Essa abertura tinha como consequência a unificação teórica mais geral entre a política e a literatura, para compreender a inevitável ressonância entre literatura artística e literatura popular na modernidade. ${ }^{6}$ A constatação da relação entre a alta e baixa literatura levou Gramsci a uma posição de confronto que tinha como base a idéia de que arte e cultura não se separam, sendo a produção literária artística e popular uma possibilidade histórica latente (Q.21, §5, p.2216). A questão principal era a de reconhecer a literatura como atividade literária, permanentemente evocada pela necessidade da participação da intelectualidade na libertação pelo povo de sua "humildade", de seu estado de passividade no capitalismo (Q.15, §58, p.1822).

Essa modalidade da relação entre intelectuais e povo, para Gramsci, foi fundada pelos jacobinos franceses, e determinou profundamente o surgimento de um tipo novo de hegemonia, bem como se tornou o eco "fantasmagórico" da literatura de todo o século XIX, não apenas na França. Essa constatação tinha por conseqüência indicações de método de análise da questão literária, já que a pesquisa sobre a beleza de uma obra estava intimamente conectada à pesquisa de por que essa obra seria lida, popular e pesquisada, ou ainda por que não atingiria o povo, não lhe interessaria (LA PORTA, 1991, p.90).

\footnotetext{
${ }^{6}$ Como veremos mais em frente, essa "unificação" entre política e literatura, entre forma e conteúdo, estava estreitamente associada à valorização, por Gramsci, das contribuições teóricas do crítico literário Francesco De Sanctis e, em menor medida, do filósofo Benedetto Croce.
} 
A reflexão da literatura em sua relação com o "jacobinismo" se manifestava no estudo da escolha, audiência e admiração que as camadas populares expressavam por determinado autor e obra, além da vida dada a determinada literatura. A literatura deveria ser, portanto, tomada em referência com as complexas relações de contato e de direção cultural e política sobre a qual essas camadas se encontram (Q.21, §4, p.2113; Q.23, §7, p.2194). A hegemonia assumia papel renovado no impulso da construção estética, o que explicava, de modo inverso, como era possível que "os heróis da literatura popular, quando entram na esfera da vida intelectual popular, se separem de sua origem literária e adquiram a validade de personagem histórico" (Q.8, §122, p.1013). A fantasia literária passava, assim, a adquirir na vida intelectual popular uma específica concretude, sendo menos importante o nome e personalidade de um autor que a "persona" do protagonista7, ou seja, o sentido mais geral que uma obra era capaz de adquirir para quem a lia (Idem, p.1013).

O momento nacional-popular, essa nova forma do equilíbrio de forças, passou a ser em Gramsci um centro articulador do estudo do modo de vida moderno através do qual o passado se converteria em elemento de vida, o que é herdado em prática social. O estudo da literatura em tempo "nacional-popular" era perigoso por que tornava "realista" o conceito de hegemonia, e realçava o fato de que "depois da criação do Estado o problema cultural se impõe em toda a sua complexidade e tende à solução coerente" (Q.16, §9, p.1863). Aqui, o Estado deveria ser pensado como "direção consciente das grandes multidões nacionais”, organismo que traduz a capacidade de um grupo social (no caso, a burguesia) em configurar uma a condução do modo de vida social moderno (Q.23, §8, p.2197).

O nacional-popular representava a atualização política do peso da experiência histórica da formação dos Estados nacionais sobre a cultura, e estabelecia a maneira pela qual se manifestavam novas necessidades e contradições históricas no período moderno. ${ }^{8}$ A unificação entre nacional e popular incidia sobre todas as atividades de cultura: abaixo da linguagem moderna, mesmo a mais cosmopolita, existiria sempre uma "profunda substância cultural mais restrita, mais nacional-popular" (Idem, p.2194, grifo nosso). A vida unitária italiana estava duplamente ameaçada, portanto, caso conduzisse seriamente a pesquisa sobre os fenômenos da cultura. Primeiro, em virtude da incapacidade das classes dominantes e de seus intelectuais afirmar uma direção nacional-popular sobre a península, de expandir seu domínio para além do

\footnotetext{
7 Nesse sentido Gramsci assinalava, por exemplo, o interesse pela pesquisa da concepção "pirandelliana" de protagonista, "que continuamente recria sua "personalidade" física e moral, que é sempre diferente mesmo sendo sempre igual” (Q.17,\$34, p. 1937).

8 É interessante observar que muitos comentadores, hostis ou não ao pensamento de Gramsci, tenderam a negligenciar o papel essencial da hegemonia como componente transformador/atualizador do estudo das relações de forças nos Cadernos (BOOTHMAN, 2008, p. 201).
} 
plano coercitivo do Estado. Segundo, quanto à possibilidade latente de percepção e insurgência contra essas classes, ou seja, pelo pânico em relação ao "programa jacobino” ser apropriado e reconduzido a termo pelas massas populares (cf. Q.19).

\section{“SE NÃO SE PODE OPERAR, É PRECISO ENSINAR" 9}

Depois de preso pelo regime fascista, em $1926^{10}$, Gramsci conseguiu permissão para escrever e substituiu sua intensa atividade política como dirigente comunista por uma igualmente intensa e permanente pesquisa (für ewig) histórica, política, cultural e teórica. Como se sabe, um dos conceitos sobre os quais o marxista sardo se deteve foi o de hegemonia. Uma das primeiras vezes que Gramsci fez menção ao termo foi numa carta à esposa, Giulia, em 03 de junho de1929, em que hegemonia apareceu associada a um aspecto da relação entre cidade e campo. Para que a cidade não perdesse sua hegemonia histórica, as novas gerações deveriam mudar seu ponto de vista, no sentido de aumentar sua prole (LC, p. 266). Da resposta a essa questão de hegemonia, concluía Gramsci, as novas gerações fariam nascer uma nova ética sexual, mais elevada. Um ano depois, entre fevereiro e novembro de 1930 ${ }^{11}$, em passagens dos Cadernos 1 e 4, a hegemonia foi apresentada como direção de classe.

No Caderno 1, Gramsci falava da possibilidade e necessidade de construção de uma "hegemonia política" antes de alcançar o Governo e deter o controle do poder material deste (Q.1, §.44, p. 41). ${ }^{12}$ No Caderno 4, Gramsci afirmou que o materialismo histórico era capaz de "começar a exercitar uma hegemonia sobre o velho mundo intelectual”, mesmo antes de ser hegemônico, na medida em que mantivesse sua autonomia como estrutura de pensamento (Q.4, §14, p.435-436).13 Nesses dois Cadernos, Gramsci apresentava toda classe dominante como dirigente (das classes aliadas) e dominante (das adversárias), bem como a importância dos intelectuais na

\footnotetext{
9 A expressão aqui remete à Maquiavel, "è stata stimata tanto questa gloria dagli uomini che non hanno mai atteso ad altro che a gloria, che non avendo possuto fare una repubblica in atto, l'hanno fatta in iscritto." (MACHIAVELLI, 1971, p. 30-31). Gramsci era consciente de que, ao ser preso, sua atividade como dirigente político estava comprometida e, em uma carta do cárcere à Tania de 10 de dezembro de 1930, escreveu sobre suas condições na prisão e as perspectivas de voltar à liberdade: "Bisogna, secondo me, essere sempre molto pratici e concreti, non sognare a occhi aperti, porsi dei fini discreti, raggiungibili e pensarli con tutte le condizioni che solo li fanno realizzare; bisogna quindi avere una perfetta coscienza dei propri limiti, se pur si vuole allargarli e approfondirli” (LC, p. 317).

${ }_{10}$ No período anterior ao cárcere, quando Gramsci esteve em Turim, acompanhando o movimento operário nas ocupações e conselhos de fábrica, hegemonia era uma palavra comum entre os socialistas italianos, que aparecia, por exemplo, no tratamento da questão da conflituosa formação linguística italiana desde o século XVIII (BOOTHMAN, 2008, p.203). Além disso, a questão das "guerras de hegemonias" era colocada pelos socialistas em 1916-1917 para tratar da questão do controle marítimo sobre o Adriático, ou para a questão nacional italiana em Trieste e Dalmácia.

${ }^{11} \mathrm{O}$ texto se orienta aqui, via de regra, pela reconstrução temporal-teórica realizada por Giuseppe Cospito (2004) a respeito do conceito de hegemonia nos Cadernos do Cárcere.

${ }_{12}$ Esse parágrafo foi reescrito posteriormente, no Caderno 19 - sobre o Risorgimento italiano.

13 Esse parágrafo foi reescrito posteriormente, no Caderno 10 - sobre a filosofia de Benedetto Croce.
} 
construção de hegemonia, um conceito direcionado aqui para compreender a construção da supremacia da classe operária. ${ }^{14}$ Nesse período, apareceu também um nexo entre as relações de classe e a luta política, que seria desenvolvido posteriormente em outras passagens dos Cadernos. A "base econômica" aparecia como determinante fundamental da construção ideológica: os intelectuais, agentes de hegemonia, estão conectados por sua origem de classe.

Já no Caderno 3, Gramsci se questionava sobre o fato das massas italianas estarem inclinadas à leitura de autores estrangeiros. Os italianos "sofriam" a hegemonia dos estrangeiros por que na Itália não existia um bloco intelectual e moral. Dessa constatação derivava um aparente "momento sociológico", articulado com a presença de uma série indefinida de acepções intermediárias, históricas, culturais e folclóricas das relações políticas na península, das quais Gramsci tinha consciência. Os intelectuais italianos "não saem do povo, não conhecem suas necessidades, aspirações e sentimentos difusos” (Q. 3, §63, p. 344).15

Foi nessa época que o marxista sardo aprofundou o tema dos instrumentos para alcance e manutenção da hegemonia, e distinguiu entre o exercício "normal" da hegemonia por uma combinação entre força e consenso, e a crise do aparato hegemônico, ou do "princípio de autoridade". Dessa forma, o conceito de hegemonia passou a exigir uma concepção das relações de forças políticas, que germinavam no pensamento de Gramsci e estavam ainda em suspensão nesse período, especialmente no Caderno 1, escrito entre fevereiro de 1929 e maio de 1930 (cf. FRANCIONI, 1984).

A primeira tentativa de sistematizar, organizar e coordenar a temática da hegemonia foi realizada no Caderno 4 (escrito entre maio de 1930 e setembro de 1932) , em que Gramsci definiu três momentos de articulação das relações de força: momento econômico-corporativo, das relações diretamente ligadas à estrutura produtiva stricto sensu; momento ético-político, que poderia ser dividido em vários momentos, correspondentes a diversos graus de consciência política, onde a questão do Estado era já colocada, mas no "terreno da igualdade política elementar"; e o momento das relações de força militares, momento estritamente político (Q.4, §38, p. 458; cf. COSPITO, 2004, p. 77).

Nesse meio tempo, em carta à cunhada Tania de 17 de setembro de 1931, Gramsci comentou sobre sua operação de extensão do conceito de intelectual, que não se restringia às noções correntes, referentes apenas aos "grandes intelectuais". Essa extensão tinha por conseqüência certas determinações sobre o conceito de Estado, incapaz de ser pensado apenas como sociedade política. Aparecia, então, a noção de

\footnotetext{
14 É interessante notar o eco nas reflexões de Gramsci dos termos colocados por Trotsky em 1905 para avaliar o movimento revolucionário russo.

15 Esse parágrafo foi reescrito posteriormente, no Caderno 21 - sobre a literatura nacional-popular.
} 
equilíbrio entre sociedade política e sociedade civil, ou exercício de "hegemonia de um grupo social sobre toda a sociedade nacional através da organização das coisas ditas privadas" (LC, p. 458-459). Essa idéia impunha, para Gramsci, a necessidade de um "ponto de vista monográfico" para compreensão de cada período histórico italiano, do Império Romano ao Risorgimento, dentro da chave do equilíbrio de forças.

De maneira semelhante, no Caderno 8, escrito entre 1931 e 1932, Gramsci apresentou a ideia de que todos os homens são filósofos, apesar de nem todos possuírem a "função filosófica" na sociedade capitalista. Aqueles que são apenas "filósofos ocasionais" não conseguiriam livrar-se da hegemonia dominante como concepção de mundo, embora como "cientistas" experimentassem uma contradição efetiva com essa concepção (Q.8, §204, p. 1063).16

Foi justamente o desenvolvimento da hegemonia, como conceito e, ao mesmo tempo, fenômeno historicamente enraizado, recuperado e transformado pela luta das classes sob o capitalismo, o que permitiu a Gramsci diferenciar-se dos "preconceitos" de Benedetto Croce e Giovani Gentille ${ }^{17}$ com relação à política, e da sociologia de Robert Michels $^{18}$ na teorização dos partidos. Em Gramsci, caberia ao partido político, intelectual coletivo, elevar o nível "econômico corporativo" ao "ético-político", estabelecendo, assim, uma relação fecunda entre espontaneidade e direção, como meio para construção de hegemonia. Além disso, dado que a relação entre espontaneidade e direção não se firmava e reproduzia apenas por meio do consenso, cada indivíduo, intelectual e filósofo, estava, a sua maneira, ligado ao cálculo permanente da correlação de forças militares.

Em 02 de maio de 1932, em carta à Tania, Gramsci destacava o fato de que Benedetto Croce, em sua atividade histórico-política, acentuava apenas o aspecto "hegemônico" da política, ou seja, aquele vinculado ao consenso, à direção cultural, de maneira a distinguir-lhe do momento da força. Para o marxista sardo, Croce pretendia com isso liquidar o marxismo em sua "teoria da história", e que o filósofo napolitano havia, de certa forma, compreendido que o aspecto essencial dos desenvolvimentos mais avançados da filosofia da práxis consistia justamente no conceito históricopolítico de hegemonia (LC, p. 570). O momento "hegemônico" era aqui associado por Gramsci ao momento do consenso, momento "ético-político", para usar um conceito crociano. A hegemonia, porém, não era apenas consenso, não poderia ser enquadrada exclusivamente no plano "ético-político", mas era um conceito "histórico-político",

\footnotetext{
${ }^{16}$ Esse parágrafo foi reescrito posteriormente, no Caderno11 - sobre o materialismo de Bukharin.

17 Foi nesse período também que Gramsci iniciou a crítica do idealismo de Croce e Gentille: no primeiro, criticou a separação entre sociedade civil e sociedade política, entre hegemonia e ditadura; no segundo, criticou o fato de hegemonia e ditadura serem indistintas, assim como sociedade civil e política, e a força o consenso (cf. COSPITO, 2004; cf. Q6, §10, p. 691).

${ }^{18}$ Cf. Q13, §33, p. 1629.
} 
ligado radicalmente e realisticamente ao esforço pela construção ou manutenção de determinado bloco histórico. ${ }^{19}$

Quando foram escritos os Cadernos 6 e 8, a hegemonia apareceu pela primeira vez como título de rubrica. Aqui, Gramsci propôs o nexo entre hegemonia e guerra de posição ("a guerra de posição, na política, é o conceito de hegemonia" ${ }^{20}$ ); a guerra de movimento, por outro lado, estaria associada à revolução permanente, conceito desenvolvido por Marx para pensar os acontecimentos entre 1848 e1871 como expressão científica do jacobinismo. A revolução permanente foi reelaborada por Gramsci no conceito de hegemonia e, ao final de 1931, Gramsci contrapôs à equiparação economicista entre classes e ideias dominantes um conceito que unificava política e cultura em sentido integral.

Nos Cadernos 12-13,16,19,22-23, escritos entre maio de 1932 e fevereiro de 1935, hegemonia foi depurada como conceito em conexão com todos os grupos sociais, mas especialmente com os dominantes. Agora, as expressões de vontade, ação, iniciativa política e intelectual passaram a ser uma emanação orgânica (e não expressão mecânica) de necessidades econômicas. A hegemonia fundia em si as dimensões éticopolítica e econômica, para conduzir a uma análise histórico-política. A análise dos diversos níveis das relações de forças deveria avançar para culminar no nível militar, que para Gramsci coincidia justamente com o fenômeno de crise de hegemonia.

A crise seria um processo profundo de desestabilização dos consensos construídos pelas classes dominantes e a exigência do uso da força para sua manutenção, paralelamente à insurgência das massas ativas politicamente, embora não necessariamente organizadas. A atividade crítica, nesse sentido, era fundamental para pensar a dificuldade de conceber o exercício real de hegemonia, para além da posse do Estado, e apontar saídas para a organização ativa das massas em novos consensos, superando a tradição burguesa. Gramsci percebia a função hegemônica como existente em cada nível da vida política, nacional e internacionalmente, e tensionada permanentemente pela instabilidade das relações de forças sociais sob o capitalismo.

\footnotetext{
19 É interessante perceber que, assim como na tradição grega clássica, "hegemônico" e "hegemonia" não possuem necessariamente o mesmo sentido. Enquanto o primeiro se refere a um momento das relações de forças sociais, a segunda, como conceito, funde em si a possibilidade da ruptura (finitude) histórica, e amplia as possibilidades analíticas.

${ }^{20} \mathrm{Q} 8, \S 52$, p. 973.
} 


\section{REFERÊNCIAS BIBLIOGRÁFICAS}

ANGLANI, Bartolo. Egemonia e poesia: Gramsci, l'arte e la letteratura. Lecce: Piero Marini, 1999.

BARATTA, Giorgio. As rosas e os cadernos: o pensamento dialógico de Antonio Gramsci. Rio de Janeiro: DP\&A, 2004.

BIANCHI, Alvaro. O laboratório de Gramsci: filosofia, história e política. São Paulo: Alameda, 2008.

BOOTHMAN, Derek. The sources for Gramsci's concept of hegemony. Rethinking Marxism, 2008. Vol. 20, n. 2.

CHIARANTE, Giuseppe. Gramsci fra tradizione e attualità. Crítica Marxista, n.3-4, p.103-12, 1988.

CICERONE, Marco Tulio. Dei doveri: a cura di Dario Arfelli; testo originale a fronte. Roma: Mondadori, 1994.

COSPITO, Giuseppe. Egemonia. In Parole di Gramsci. Roma: Carocci, 2004.

DE SANCTIS, Francesco. La democrazia ideale e reale. Napoli: Alfredo Guida, 1998.

DIAS, Edmundo Fernandes. Do giolitismo à guerra mundial. Textos Didáticos, n.39. IFCH/Unicamp, outubro de 2004.

D’ORSI. Angelo. Egemonia. Uma parola controversa In D’ORSI, A. (org.) Egemonie. Napoli: Dante \& Descarte, 2008.

FRANCIONI, Gianni. L’Officina Gramsciana. Napoli: Bibliopolis, 1984.

GRAMSCI, Antonio. Cadernos do Cárcere. Rio de Janeiro: Civilização Brasileira, 2001- 2006, 6v.

Lettere dal Carcere. Palermo: A. Santucci, 1996, 2 v.

Quaderni del Carcere.Torino: G. Einaudi, 1975, 4v.

KANOUSSI, Dora. Los Cuadernos filosoficos de Antonio Gramsci: de Bujarin a Maquiavelo. Ciudad de Mexico: Plaza y Valdés, 2007.

LANDY, Marcia. Culture and Politics in the Work of Antonio Gramsci. Boundary 2, Vol. 14, n.3, p.49-70, 1986.

LA PORTA, Lelio. Lukács, Gramsci e la letteratura italiana. Crítica Marxista, n.2, p.85-96, 1991.

LIGUORI, Guido. Roteiros para Gramsci. Rio de Janeiro: Editora UFRJ, 2007.

LENIN, V. I. Obras Completas. Madrid: Akal, 1976a. Tomo V.

Obras Completas. Madrid: Akal, 1976b. Tomo VIII.

Obras Completas. Madrid: Akal, 1976c. Tomo XII. 
Obras Completas. Madrid: Akal, 1977a. Tomo XIII

. Obras Completas. Madrid: Akal, 1977b. Tomo XVI.

Obras Completas. Madrid: Akal, 1977c. Tomo XVII

. Collected Works. Moscow: Progress Publisher, 1965. Vol. 29.

MACHIAVELLI, Niccólo. Tutte le opere. Florença: Sansoni, 1971.

PETRONIO, Giuseppe. Gramsci e i problemi della letteratura. In Gramsci e la cultura contemporanea I. Roma: Editori Riuniti, p.287-295, 1975.

SALINARI, Carlo. Gramsci e i problemi della letteratura. In Gramsci e la cultura contemporanea I. Roma: Editori Riuniti, p.284-286, 1975.

SAPEGNO, Natalino. Gramsci e i problemi della letteratura. In Gramsci e la cultura contemporanea I. Roma: Editori Riuniti, p.265-277, 1975.

TACITO, Cornelio. Storie: introduzione, traduzione e note di Mario Stefanoni, com um saggio di Mario Pani. Milano: Garzanti, 2005.

TROTSKY, Leon. 1905: resultados y perspectivas. França: Ruedo Ibérico, 1971.

Entre el imperialismo y la revolucion. México D. F.: Roca, 1973.

Literatura e revolução. 2 ed. Rio de Janeiro: Jorge Zahar, 1980.

VIVANTI, Corrado. Hegemonia/ditadura. In Enciclopédia Einaudi, volume 22. Edição portuguesa: Imprensa Nacional-Casa da Moeda, 1996.

VOZA, Pasquale. Intelletuali In (LIGUORI, G. e VOZA, P. (cura di) Dizionario Gramsciano (1926-1937). Bari: Omnibook, 2009. 